Check for updates

Cite this: RSC Adv., 2018, 8, 24392

\title{
Heteroatom-doped nanoporous carbon from recyclable Pueraria lobata and its dual activities for oxygen reduction and hydrogen evolution reactions $\dagger$
}

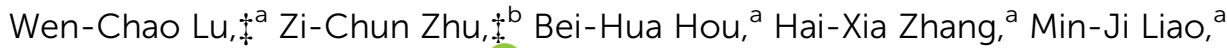 \\ Zhen-Yu Wu*a and Ping Chen (iD *a
}

\begin{abstract}
Many efficient and non-precious metal catalysts for oxygen reduction or hydrogen evolution reactions have been developed, but bifunctional catalysts for both oxygen reduction reaction and hydrogen evolution reactions are seldom reported despite their advantages. Herein, we designed the bulk preparation of heteroatom-doped nanoporous carbon catalysts using widely available and recyclable Pueraria lobata powder as the carbon source. The typical product was N, P and Fe Tri-doped nano-porous carbon (N,P,Fe-NPC) with high surface area (BET surface area of $776.68 \mathrm{~m}^{2} \mathrm{~g}^{-1}$ and electrochemical surface area of $55.0 \mathrm{mF} \mathrm{cm}{ }^{-2}$ ). The typical N,P,Fe-NPC sample simultaneously exhibited high activities for oxygen reduction and hydrogen evolution reactions. Because of the high surface area and the tri-doping of N, P and Fe elements, the prepared material may have applications in other fields such as gas uptake, sensors, sewage treatment, and supercapacitors. The suggested approach is low-cost, simple and readily scalable.
\end{abstract}

Received 25th April 2018

Accepted 20th June 2018

DOI: $10.1039 / \mathrm{c} 8 \mathrm{ra0} 3572 \mathrm{e}$

rsc.li/rsc-advances improve the energy efficiency, it may be possible to design a device for the combination of water decomposition and the fuel cell. Currently, many significant ORR and HER catalysts have been developed, but bifunctional catalysts for both ORR and HER are seldom reported despite their importance. ${ }^{\mathbf{1 0 , 1 1}}$

So far, the noble metal Pt has been recognized as an excellent catalyst for ORR and HER; however, its disadvantage is its global scarcity. ${ }^{12}$ Therefore, it is necessary to find alternative catalysts that have low prices and bulk production. In the past several years, many effective catalysts for HER have been reported. Nonprecious metal (Ni, Co, Fe, Mo and $\mathrm{W}$ )-based nanocomposites have good catalytic performance for HER. ${ }^{\mathbf{9 , 1 1 , 1 3}}$

Recently, heteroatom (e.g., N, B, P and S)-doped carbon materials have been developed as effective non-precious metal electrocatalysts for ORR. ${ }^{\mathbf{1 4 , 1 5}}$ Some $\mathrm{N}$-doped carbon materials (e.g., mesoporous carbon, carbon nanotubes, ${ }^{3}$ graphene and carbon nanotube-graphene complex ${ }^{\mathbf{1 6 , 1 7}}$ ) have shown excellent activities and stabilities. It was reported that carbon materials with the co-doping of certain transition-metal elements (e.g., Co and $\mathrm{Fe}$ ) and nitrogen showed a remarkable promotion of the ORR activity in acidic or alkaline media, because of the coordination between the transition-metal cation and nitrogen. With respect to the electrocatalysts of HER or ORR, it is very important to obtain catalysts with large surface areas and interpenetrated network structures, which effectively accelerate the reactant and electron transport. ${ }^{17,18}$ Nanoscale porosity is highly desirable and can facilitate high mass transfer fluxes.
230601, P. R. China. E-mail: chenping@ahu.edu.cn; wuzhenyuhn@163.com

${ }^{b}$ School of Chemistry and Materials Engineering, Chizhou University, Chizhou, Anhui, 247000, P. R. China

$\dagger$ Electronic supplementary information (ESI) available. See DOI: 10.1039/c8ra03572e

\$ These authors (Wen-Chao Lu and Zi-Chun $\mathrm{Zhu}$ ) have the equal contribution to this paper. 
Recently, considerable attention has been paid to carbon materials derived from biomass, because biomass is widely available, accessible and recyclable. Preparation of carbon materials from biomass is meaningful and crucial since it has potential applications. Pueraria lobata is a perennial vine native to Southeast Asia. It is commonly known as kudzu root or Gegen. The powder of Pueraria lobata can be obtained from the dried root of Pueraria lobata, and it contains many polysaccharides. This powder has been used as a functional food and as a medicinal herb for treating dysentery, fever, diabetes, hypertension, etc. ${ }^{\mathbf{1 9}}$ Every year, large quantities of biomass are produced (powder of Pueraria lobata), and they are available at no (or low) cost. $^{\mathbf{2 0 , 2 1}}$ Therefore, the powder of Pueraria lobata is an excellent choice for the bulk production of carbon materials as electrocatalysts with low cost.

Recently, we focused on carbon-based ORR electrocatalysts. We reported the nitrogen-doped graphene/carbon nanotube nanocomposite and discussed its synergistic effect on ORR activities. ${ }^{17}$ We prepared the $\mathrm{N}$-doped carbon framework with $\mathrm{Co} / \mathrm{Co}_{3} \mathrm{O}_{4}$ nanoparticles and found that improving the conductivity of the nanocomposite and doping of the $\mathrm{N}$ element contributed to the improvement of electrochemical activity. ${ }^{22}$ We also prepared nitrogen-doped nanoporous carbon nanosheets from the recyclable plant Typha orientalis, and we found that the doping of nitrogen and high surface area were helpful for obtaining high ORR activity and stability. ${ }^{18} \mathrm{~N}-$, Fe- and Cotridoped carbon nanotube/nanoporous carbon ${ }^{23}$ and CMK3/ graphene-N-Co nanocomposite ${ }^{24}$ were prepared, and their ORR activities clearly increased because of the N-, Fe- and (or) Codoping. Very recently, we reported nanoporous ORR electrocatalysts from the corn silk of the corn plant. ${ }^{25}$

Based on the above-mentioned discussion and our previous studies, herein, we reported the bulk preparation of an $\mathrm{N}, \mathrm{P}$ and Fe tridoped nano-porous carbon (N,P,Fe-NPC) catalyst using widely available and recyclable Pueraria lobata powder as the carbon source. The typical product exhibited high surface area and high total pore volume. Importantly, the catalyst simultaneously exhibited high activities for ORR and HER.

\section{Experimental method}

\section{Materials}

Pueraria lobata powder was purchased from Zhongxiang Pueraria powder Industrial Co., Ltd. (Hubei, China). $\mathrm{Fe}\left(\mathrm{NO}_{3}\right)_{3}$ - $9 \mathrm{H}_{2} \mathrm{O}$ (analytical reagent) and $\mathrm{KOH}$ were brought from Aladdin Industrial Corporation (Shanghai, China). $\mathrm{H}_{3} \mathrm{PO}_{4}$ (analytical reagent) was brought from Sinopharm Chemical Reagent Co., Ltd. (Shanghai, China). $\mathrm{NH}_{3}$ (99.99\%) was brought from Shang Yuan Company (Nanjing, China).

\section{Preparation of typical N,P,Fe-NPC}

First, $2.7 \mathrm{~g}$ of $\mathrm{Fe}\left(\mathrm{NO}_{3}\right)_{3} \cdot 9 \mathrm{H}_{2} \mathrm{O}$ was dissolved in $50 \mathrm{~mL}$ of deionized water and then, Pueraria lobata powder was added to form a mixture; next, $97.0 \mathrm{~mL}$ of $0.2 \mathrm{M} \mathrm{H}_{3} \mathrm{PO}_{4}$ was put into $162.5 \mathrm{~mL}$ of boiling water, and this was added to the mixture to form a gel. After washing by filtration and freeze-drying for $12 \mathrm{~h}$, the precursor was obtained. For the final product, the precursor was annealed in $\mathrm{NH}_{3}$ atmosphere at $950{ }^{\circ} \mathrm{C}$ for $1 \mathrm{~h}$ with a heating rate of $5{ }^{\circ} \mathrm{C} \mathrm{min}^{-1}$.

As the control, the product- $\mathrm{N}_{2}$ was prepared by the same method used for N,P,Fe-NPC, but it was annealed in an $\mathrm{N}_{2}$ atmosphere at $950{ }^{\circ} \mathrm{C}$ for $1 \mathrm{~h}$ with a heating rate of $5{ }^{\circ} \mathrm{C} \mathrm{min}^{-1}$.

\section{Characterization}

An ESCALAB MKII X-ray photoelectron spectrometer was used to obtain X-ray photoelectron spectroscopy (XPS) data. An XD-3 $\mathrm{X}$-ray diffractometer was used to record the X-ray diffraction patterns (XRD). The scanning electron microscopy images were obtained by a JEOL-6700F field emission scanning electron microscope. The scanning transmission electron microscopy (STEM) images were recorded on JEM-2100F. The BET specific surface area was measured by a Micrometrics ASAP2020 analyzer (USA).

\section{Electrochemical activities}

HER and ORR performances of the samples were measured using the CHI750E electrochemical workstation (Shanghai Chenhua, China) with a rotating disk glassy carbon electrode by the conventional three-electrode method at room temperature. The ink of each sample was prepared as follows: $5 \mathrm{mg}$ of the catalyst was dispersed in $1 \mathrm{~mL}$ of $3: 1 \mathrm{v} / \mathrm{v}$ deionized water/ isopropanol mixed solvent containing $40 \mu \mathrm{L}$ of Nafion solution (5 wt $\%$ ). Then, the mixture was ultrasonicated for $40 \mathrm{~min}$ to achieve a homogeneous catalyst ink. ${ }^{16,26,27}$ Finally, $10 \mu \mathrm{L}$ of the ink was adhered on to the GC disk electrode, forming the catalyst loading of $0.250 \mathrm{mg} \mathrm{cm}^{-2}$ for ORR and HER measurements.

HER performance. Rotating disk glassy carbon electrode (GC, PINE, $5 \mathrm{~mm}$ diameter, $0.196 \mathrm{~cm}^{2}$ ), $\mathrm{Ag} / \mathrm{AgCl}$ (saturated by $\mathrm{KCl})$ electrode and a graphite rod were used as the working electrode, reference electrode and the auxiliary electrode, respectively. Polarization curves were obtained with a scan rate of $5 \mathrm{mVs}^{-1}$ and a speed of $1600 \mathrm{rpm}$ in $0.5 \mathrm{M} \mathrm{H}_{2} \mathrm{SO}_{4}$ and $0.1 \mathrm{M}$ $\mathrm{KOH}$. Cyclic voltammograms (CVs) were obtained at different rates from 20 to $200 \mathrm{mV} \mathrm{s}^{-1}$. The iR-compensation was used in the measurements.

ORR performance. Rotating disk glassy carbon electrode (GC, PINE, $5 \mathrm{~mm}$ diameter, $0.196 \mathrm{~cm}^{2}$ ), $\mathrm{Hg} / \mathrm{HgO}$ electrode and a platinum plate were used as the working electrode, reference electrode and the auxiliary electrode, respectively. The working electrode was scanned at a rate of $20 \mathrm{mV} \mathrm{s}^{-1}$ with rotating speed from $400 \mathrm{rpm}$ to $2000 \mathrm{rpm}$ in $\mathrm{O}_{2}$-saturated $0.1 \mathrm{M} \mathrm{KOH}$.

Potentials were converted to the RHE reference scale.

\section{Results and discussion}

\section{Preparation}

Scheme 1 illustrates the typical N,P,Fe-NPC preparation; the procedure contains the following steps: First, the Pueraria lobata powder was obtained from the mechanical grinding of a Pueraria root. The Pueraria lobata powder sol was formed by adding $\mathrm{Fe}\left(\mathrm{NO}_{3}\right)_{3} \cdot 9 \mathrm{H}_{2} \mathrm{O}$. The Pueraria sol contained many 


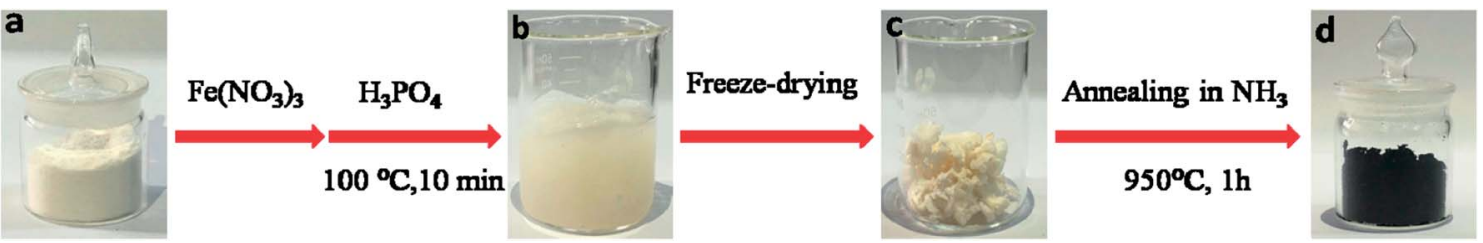

Scheme 1 Illustration of the typical N,P,Fe-NPC preparation. Photographs of Pueraria lobata powder (a), Pueraria lobata gel containing $\mathrm{H}_{3} \mathrm{PO}_{4}$ and $\mathrm{Fe}\left(\mathrm{NO}_{3}\right)_{3} \cdot 9 \mathrm{H}_{2} \mathrm{O}(\mathrm{b})$, the material precursor obtained from the gel (c), and typical N,P,Fe-NPC (d).

functional groups such as hydroxyl and carboxyl groups, which can coordinate with $\mathrm{Fe}^{3+}$. Then, $\mathrm{H}_{3} \mathrm{PO}_{4}$ in boiling water was added to the sol, and the Pueraria gel was immediately formed. Second, the material precursor having $\mathrm{P}$ and Fe was obtained from the gel by freeze-drying. Finally, N,P,Fe-NPC was achieved by heat treatment in $\mathrm{NH}_{3}$, where carbonization occurred, and $\mathrm{N}$, $\mathrm{P}$ and Fe were tri-doped in the carbon sample. $\mathrm{NH}_{3}$ was not only used as the $\mathrm{N}$ source to dope the carbon but also to gasify the carbon to form many nanopores.

The main possible reactions can be expressed as follows: $\mathbf{1 8 , 2 8 , 2 9}^{-10}$

$$
\begin{gathered}
2 \mathrm{NH}_{3} \rightarrow \mathrm{N}_{2}+3 \mathrm{H}_{2} \\
\mathrm{C}+2 \mathrm{H}_{2} \rightarrow \mathrm{CH}_{4}
\end{gathered}
$$

Doped $\mathrm{Fe}$ was obtained from $\mathrm{Fe}\left(\mathrm{NO}_{3}\right)_{3} \cdot 9 \mathrm{H}_{2} \mathrm{O}$, and $\mathrm{P}$ was obtained from $\mathrm{H}_{3} \mathrm{PO}_{4} ; \mathrm{N}$ was obtained mainly from $\mathrm{NH}_{3}$. Pueraria powder is a widely available and recyclable plant biomass. N,P,Fe-NPC preparation is a low-cost, simple and readily scalable approach. It is of great importance to design bulk production of carbon-based nanomaterials from available and recyclable biomass by a low-cost method.

\section{Characterization}

According to SEM images (shown in Fig. 1a-c), typical N,P,FeNPC is made up of carbon sheets with many pores; the diameters of these pores range from 0.9 to $3.5 \mu \mathrm{m}$.

The STEM image of typical N,P,Fe-NPC is shown in Fig. 2a, from which it can be deduced that the typical product has a clear nanoporous structure. The elemental mapping images (Fig. 2b-f) show the distribution of C, N, O, P and Fe. The results indicate the presence of $\mathrm{C}, \mathrm{N}, \mathrm{O}, \mathrm{P}$ and Fe; they are homogeneously distributed in the sample. With respect to the control sample, the product- $\mathrm{N}_{2}$ has a clear porous structure, as shown in Fig. S1a and b.†
According to the results of X-ray photoelectron spectroscopy (XPS), typical N,P,Fe-NPC exhibits the atomic percentages of 6.43 at $\%, 1.54 \%, 1.11$ at\%, 76.59 at\% and 14.33 at\% for N, P, Fe, $\mathrm{C}$ and $\mathrm{O}$, respectively. Fig. 3a indicates that typical N,P,Fe-NPC contains pyridinic (398.3 eV), pyrrolic (399.7 eV) and graphitic $(401.0 \mathrm{eV}) \mathrm{N}^{\mathbf{1 8 , 3 0}}$ The high-resolution P 2p XPS spectra (Fig. 3b) show that typical N,P,Fe-NPC exhibits four peaks at $129.4 \mathrm{eV}$, $130.1 \mathrm{eV}, 132.8 \mathrm{eV}$, and $133.6 \mathrm{eV}$. The peak at $132.8 \mathrm{eV}$ is assigned to the $\mathrm{P}-\mathrm{C}$ bond, and the peak at $133.6 \mathrm{eV}$ can be assigned to the $\mathrm{P}-\mathrm{N}$ bond. ${ }^{25}$ Fig. $3 \mathrm{c}$ indicates that $\mathrm{Fe}(\mathrm{II})$ ions (peaks at $709.0 \mathrm{eV}$ and $713.2 \mathrm{eV}$ ) $23,25,26$ exist in the typical N,P,FeNPC sample. These results indicate that the elements $\mathrm{N}, \mathrm{P}$, and Fe are doped in N,P,Fe-NPC. As the control, the product- $\mathrm{N}_{2}$ has the atomic percentages of 2.19 at\%, 0.94\%, 0.62 at\%, 75.62 at $\%$ and 20.63 at\% for N, P, Fe, C and O, respectively. Clearly, the product- $\mathrm{N}_{2}$ has lower $\mathrm{N}$ content than the typical N,P,Fe-NPC sample. Fig. S1c $\dagger$ indicates that the product- $\mathrm{N}_{2}$ contains pyridinic and graphitic N. From the Fig. S1d † (high-resolution P 2p XPS spectra), it can be seen that the product- $\mathrm{N}_{2}$ exhibits a peak at $133.6 \mathrm{eV}$, which can be assigned to the $\mathrm{P}-\mathrm{N}$ bond. The XRD data (Fig. 3d) demonstrate that the state of the carbon is amorphous. From Fig. 3e and f, the BET surface area, the total pore volume and the micropore volume of the typical N,P,FeNPC sample are found to be $773.7 \mathrm{~m}^{2} \mathrm{~g}^{-1}, 0.74 \mathrm{~cm}^{3} \mathrm{~g}^{-1}$ and $0.28 \mathrm{~cm}^{3} \mathrm{~g}^{-1}$, respectively. As a control, the product- $\mathrm{N}_{2}$ has a BET surface area of $458.0 \mathrm{~m}^{2} \mathrm{~g}^{-1}$. Clearly, the typical N,P,FeNPC sample has higher BET surface area than the product- $\mathrm{N}_{2}$.

\section{Electrochemical activity for HER}

Electrochemical activities of the samples (including that of commercial Pt/C) for HER were investigated in $0.5 \mathrm{M} \mathrm{H}_{2} \mathrm{SO}_{4}$ and $0.1 \mathrm{M} \mathrm{KOH}$. Fig. 4a shows the polarization curves for typical N,P,Fe-NPC, commercial Pt/C and product- $\mathrm{N}_{2}$ in $0.5 \mathrm{M}$ $\mathrm{H}_{2} \mathrm{SO}_{4}$ with a scan rate of $5 \mathrm{mV} \mathrm{s}^{-1}$. When the current density was $10 \mathrm{~mA} \mathrm{~cm} \mathrm{~cm}^{-2}$, the potentials of typical N,P,Fe-NPC,
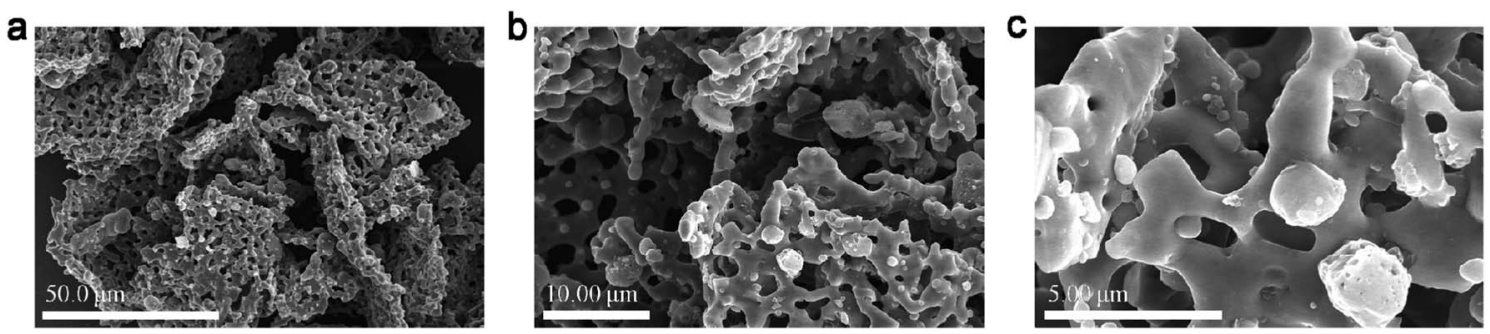

Fig. $1(\mathrm{a}-\mathrm{c})$ The representative SEM image and the magnified SEM image of typical N,P,Fe-NPC. 

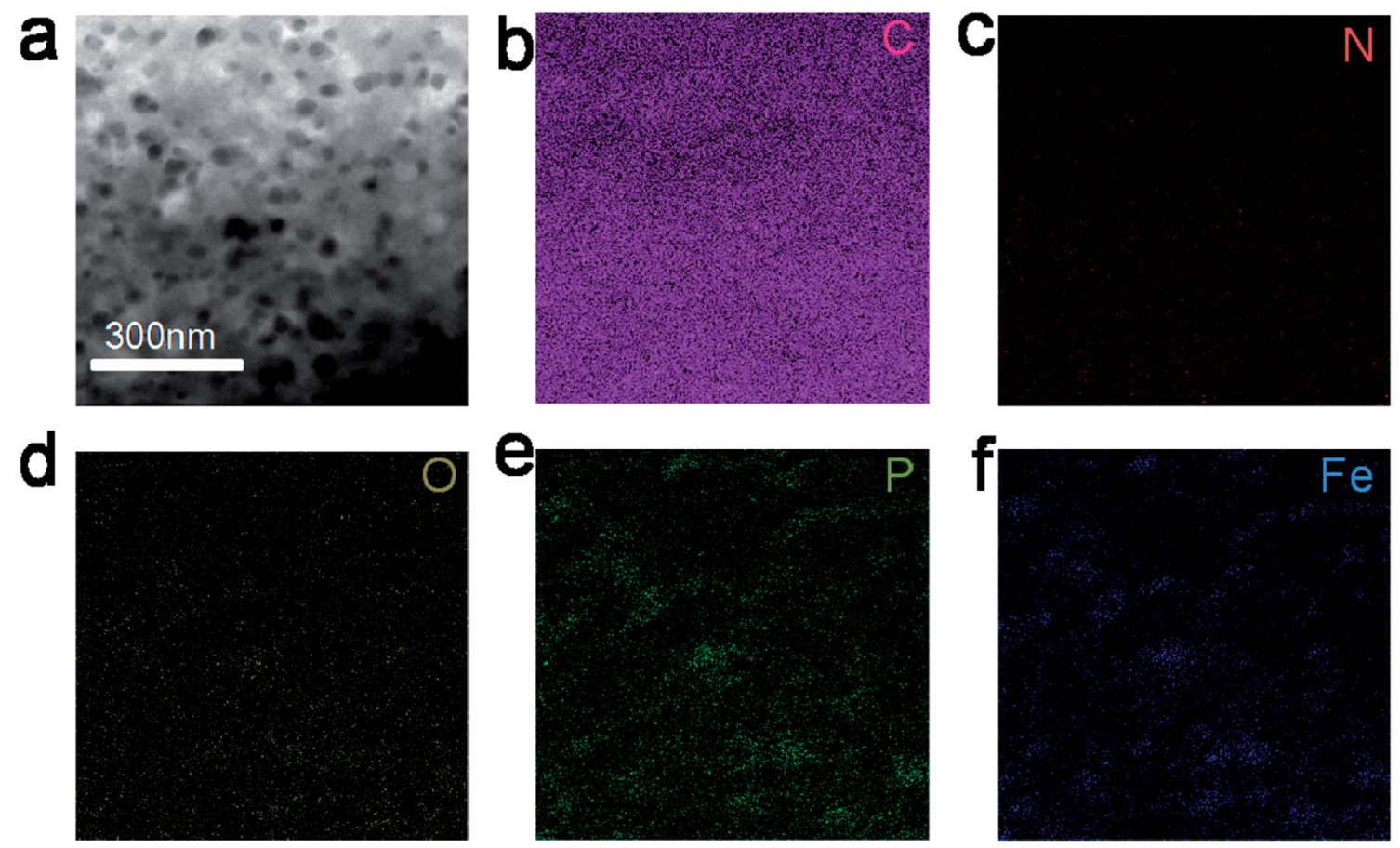

Fig. 2 (a) STEM image of typical N,P,Fe-NPC; (b-f) C, N, O, P and Fe elemental mappings.

commercial Pt/C and product $-\mathrm{N}_{2}$ were $-0.073 \mathrm{~V},-0.039 \mathrm{~V}$ and $-0.427 \mathrm{~V}$, respectively. Clearly, typical N,P,Fe-NPC showed good performance for HER, which was only $34 \mathrm{mV}$ more negative than that of the state-of-the-art Pt/C sample. Compared with the product- $\mathrm{N}_{2}$ (as a control), the typical N,P,Fe-NPC exhibited remarkably high activity for HER. Stability is important for HER electrocatalyst in practical applications. Fig. $4 \mathrm{~b}$ gives the current-time $(i-t)$ chronoamperometric response of typical N,P,Fe-NPC at $-0.076 \mathrm{~V}$ ( $v s$. RHE) for 20000 seconds in $\mathrm{N}_{2}$-saturated $0.5 \quad \mathrm{M} \mathrm{H}_{2} \mathrm{SO}_{4}$. According to Fig. $4 \mathrm{~b}$, the typical N,P,Fe-NPC sample suffered only $5.0 \%$ decrease in current density. Fig. $4 \mathrm{~b}$ indicates that typical N,P,Fe-NPC has good durability. Fig. 4c shows the polarization curves of typical N,P,Fe-NPC and commercial Pt/C in $0.1 \mathrm{M} \mathrm{KOH}$. The
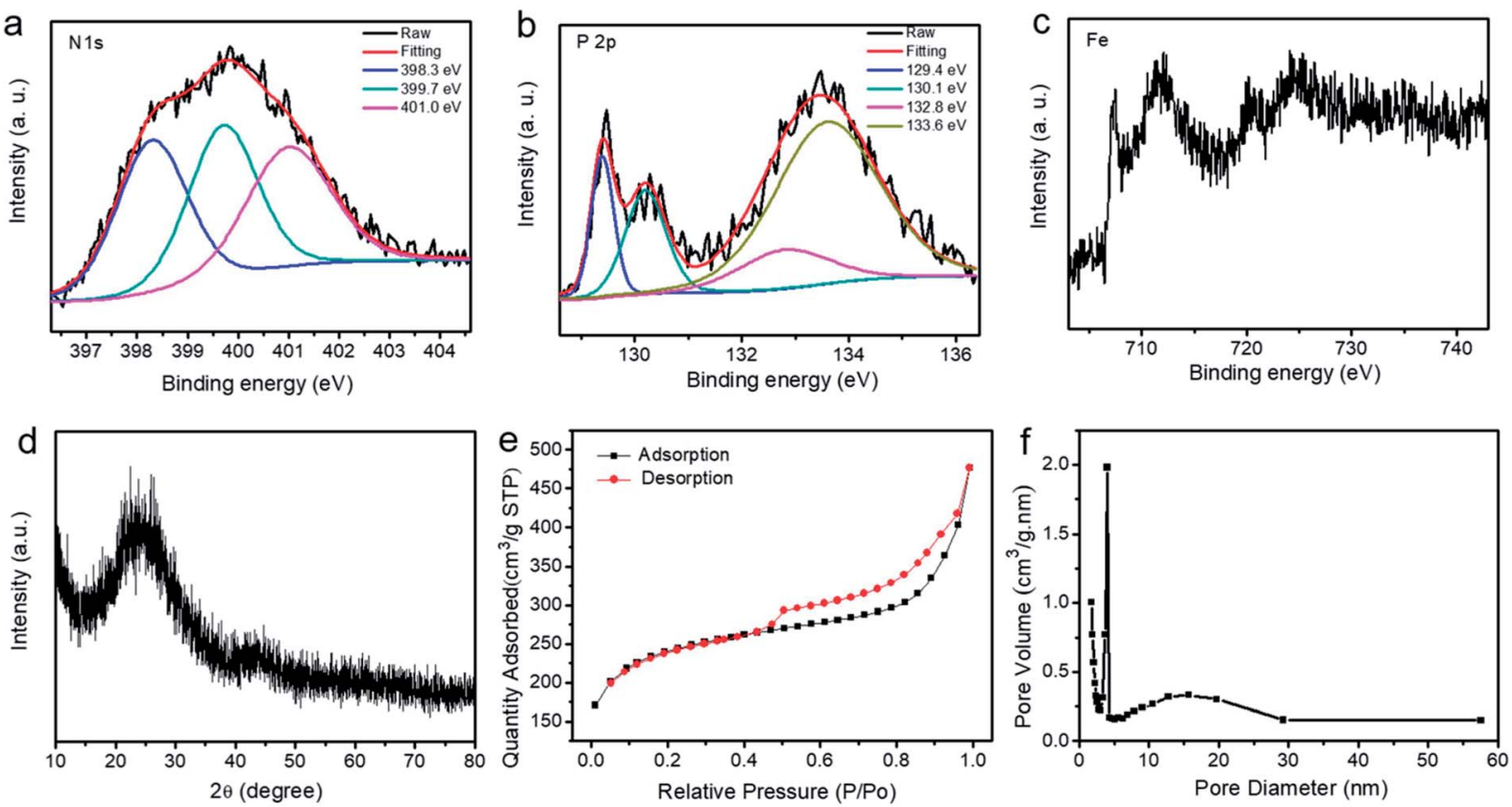

Fig. $3(a-c)$ The high-resolution N 1s, P 2p and Fe 2p XPS spectra of typical N,P,Fe-NPC; (d) X-ray diffraction pattern of typical N,P,Fe-NPC; (e and f) the nitrogen adsorption-desorption isotherm and the pore distribution of typical N,P,Fe-NPC. 

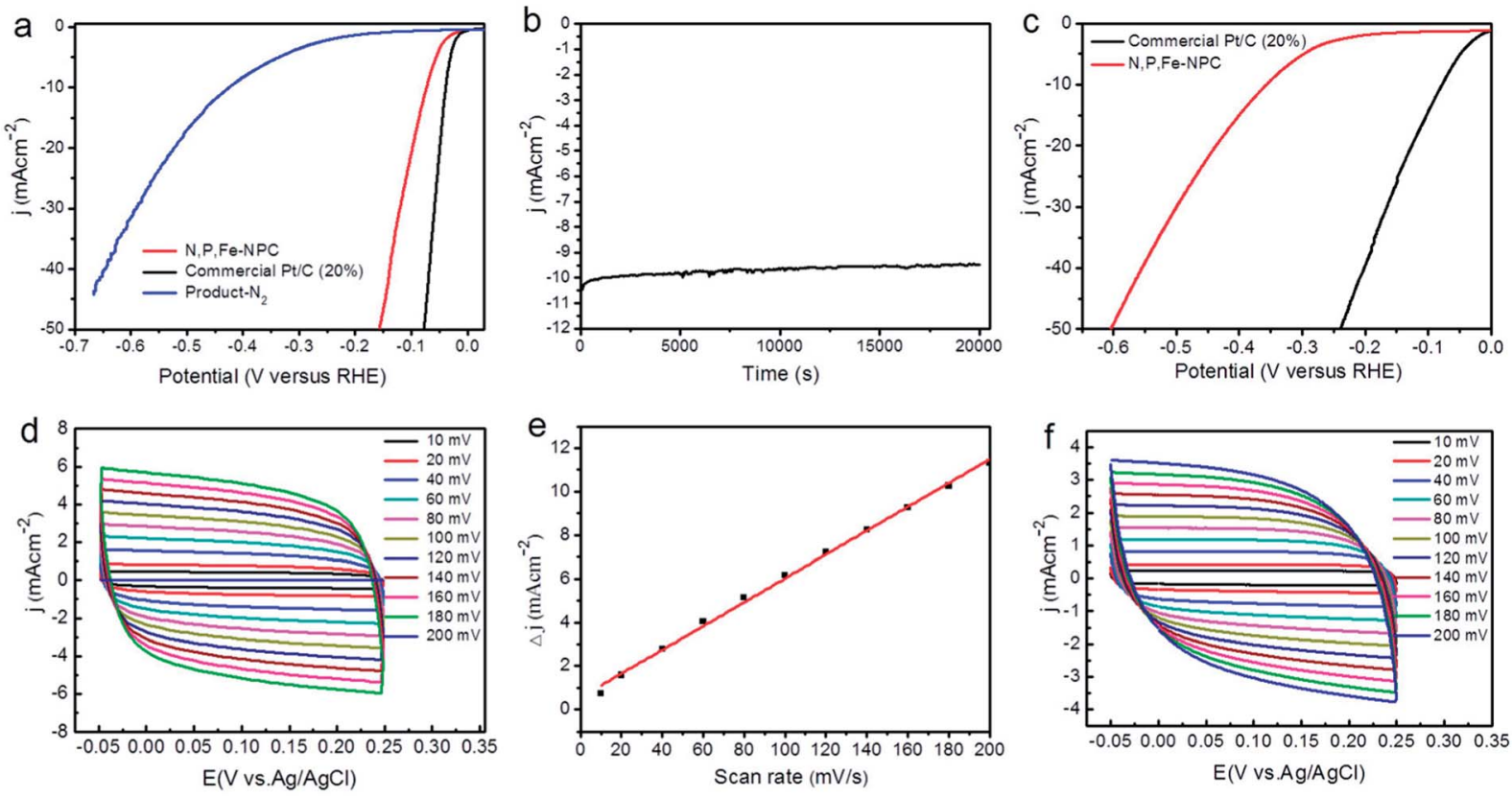

Fig. 4 (a) Polarization curves for typical N,P,Fe-NPC, commercial Pt/C and product- $\mathrm{N}_{2}$ in $0.5 \mathrm{M} \mathrm{H}_{2} \mathrm{SO}_{4}$ with a scan rate of $5 \mathrm{mV} \mathrm{s}{ }^{-1}$. (b) Currenttime $(i-t)$ chronoamperometric response of typical N,P,Fe-NPC at $-0.076 \mathrm{~V}$ (vs. RHE) in $\mathrm{N}_{2}$-saturated $0.5 \mathrm{M} \mathrm{H}_{2} \mathrm{SO}_{4}$ at a rotation rate of 1600 rpm. (c) Polarization curves for typical N,P,Fe-NPC and commercial Pt/C in $0.1 \mathrm{M} \mathrm{KOH}$ with a scan rate of $5 \mathrm{mV} \mathrm{s}{ }^{-1}$ (d) CVs for typical N,P,Fe-NPC with different rates from 20 to $200 \mathrm{mV} \mathrm{s}^{-1}$. (e) Capacitive current at $0.10 \mathrm{~V}$ as a function of the scan rate for typical N,P,Fe-NPC $\left(\Delta j_{0}=j_{a}-j_{c}\right.$ ). (f) $C V s$ for the product- $\mathrm{N}_{2}$ (as a control) with different rates from 20 to $200 \mathrm{mV} \mathrm{s}^{-1}$.

state-of-the-art $\mathrm{Pt} / \mathrm{C}$ sample $\left(-0.078 \mathrm{~V}\right.$ at $\left.-10 \mathrm{~mA} \mathrm{~cm}^{-2}\right)$ showed excellent HER activity. Typical N,P,Fe-NPC $(-0.355 \mathrm{~V}$ at $-10 \mathrm{~mA}$ $\mathrm{cm}^{-2}$ ) also showed good performance for HER, which was about $270 \mathrm{mV}$ more negative than Pt/C.

To estimate the electrochemical surface area (ESA), we measured the capacitance of the double layer. The cyclic voltammograms (CVs) were obtained in the region from -0.05 to $0.25 \mathrm{~V}$, where the current response is only due to the charging of the double layer (Fig. 4d). Fig. 4e shows the capacitive current at $0.10 \mathrm{~V}$ as a function of the scan rate for typical N,P,Fe-NPC $\left(\Delta j_{0}\right.$ $=j_{\mathrm{a}}-j_{\mathrm{c}}$ ). From Fig. $4 \mathrm{~d}$ and e, the capacitance of typical N,P,FeNPC was found to be $55.0 \mathrm{mF} \mathrm{cm}{ }^{-2}$. Therefore, we inferred that the typical N,P,Fe-NPC sample had high surface area. Fig. 4f gives CVs of the product- $\mathrm{N}_{2}$, which were obtained in the region from -0.05 to $0.25 \mathrm{~V}$. From Fig. $4 \mathrm{f}$ and $\mathrm{S} 2, \dagger$ we can infer that the product- $\mathrm{N}_{2}$ (as a control) had a capacitance of $29.0 \mathrm{mF} \mathrm{cm}^{-2}$. Clearly, the typical N,P,Fe-NPC sample had higher ESA than the product- $\mathrm{N}_{2}$.

\section{Electrochemical activity for ORR}

Rotating disk electrode (RDE) measurements were performed to investigate the ORR activities. Electrochemical activities of the samples (including that of commercial Pt/C) were investigated in $0.1 \mathrm{M} \mathrm{KOH}$. From Fig. $5 \mathrm{a}$, the onset potentials of commercial $\mathrm{Pt} / \mathrm{C}(20 \%)$ and typical N,P,Fe-NPC were found to be 932 and $957 \mathrm{mV}$ ( $v s$. RHE), respectively. Clearly, the onset potential of N,P,Fe-NPC was $25 \mathrm{mV}$ more positive than that of Pt/C. In addition, the half-wave potential of N,P,Fe-NPC ( $862 \mathrm{mV} v s$. RHE) was $32 \mathrm{mV}$ more positive than that of Pt/C ( $830 \mathrm{mV} v s$. RHE). This indicated that N,P,Fe-NPC had superior activity compared to commercial Pt/C in alkaline media, and it also exhibited superior activity than most of the non-precious metal ORR catalysts reported in literature. ${ }^{14,16,24,25,31-34} \mathrm{Fig}$. $5 \mathrm{~b}$ gives the RDE voltammograms of typical N,P,Fe-NPC at different rotation speeds. Koutecky-Levich plots (Fig. 5c) were used to analyze the number of electrons transferred during ORR. The KouteckyLevich equation is as follows: ${ }^{18,34,35}$

$$
\frac{1}{i}=\frac{1}{i_{\mathrm{k}}}=\frac{1}{B \omega^{1 / 2}}
$$

here, $j$ stands for the measured current density, $j_{\mathrm{k}}$ stands for the kinetic-limiting current density and $\omega$ stands for the electrode rotation rate; $B$ is the value of the Levich slope, which can be obtained from the following formula: ${ }^{18,34}$

$$
B=0.62 n F C_{\mathrm{O}_{2}} D_{\mathrm{O}_{2}}{ }^{2 / 3} \nu^{-1 / 6}
$$

here, $n$ is the transferred-electron number in the ORR process, $F$ is the faradaic constant $\left(96485 \mathrm{C} \mathrm{mol}^{-1}\right), C_{\mathrm{O}_{2}}$ is the oxygen concentration in $0.1 \mathrm{M} \mathrm{KOH}\left(1.2 \times 10^{-6} \mathrm{~mol} \mathrm{~cm}^{-3}\right), D_{\mathrm{O}_{2}}$ is the oxygen diffusion coefficient in $0.1 \mathrm{M} \mathrm{KOH}\left(1.90 \times 10^{-5} \mathrm{~cm}^{2} \mathrm{~s}^{-1}\right)$ and $\nu$ is the kinematic viscosity of $0.1 \mathrm{M} \mathrm{KOH}\left(0.01 \mathrm{~cm}^{2} \mathrm{~s}^{-1}\right){ }^{36,37}$

As shown in Fig. 5c, a good linear relationship between $\omega^{-1 / 2}$ and $j^{-1}$ can be achieved, from which we can obtain $n$ from 3.92 to 3.96 at potentials from 0.30 to $0.60 \mathrm{~V}$ (vs. RHE). Clearly, a fourelectron pathway for the ORR process occurs on the typical N,P,Fe-NPC electrode. To maximize the energy capacity, four-electron pathways are highly necessary for $\mathrm{O}_{2}$ reduction., ${ }^{3,38}$

During the actual operation of the fuel cell, fuel molecules (for example, methanol) may migrate onto the cathode; thus, the ORR electrocatalysts are required to exhibit tolerance to fuel 

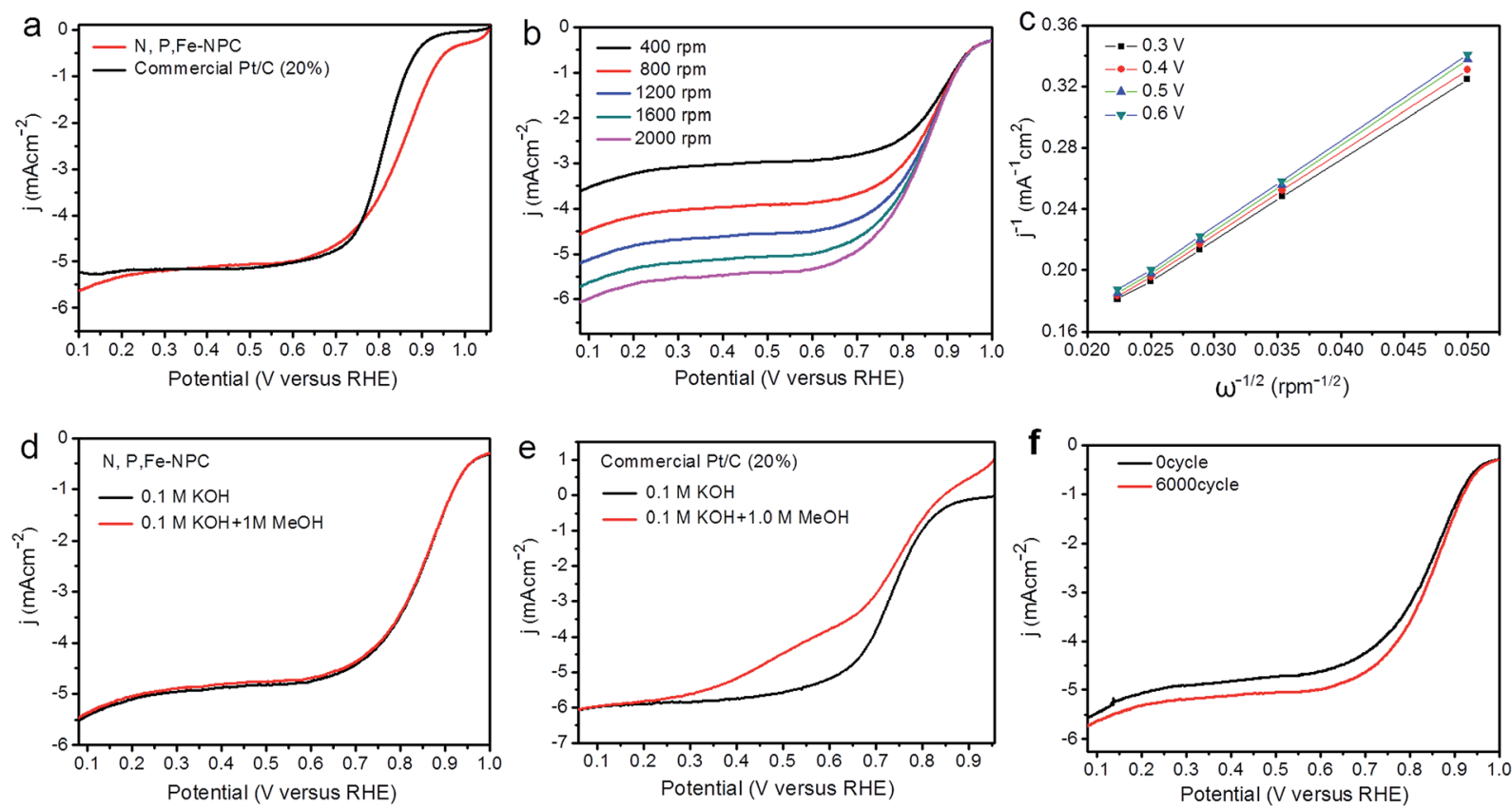

Fig. 5 (a) RDE voltammograms in $0.1 \mathrm{M} \mathrm{KOH}$ (at a rotation speed of $1600 \mathrm{rpm}$ ) for typical N,P,Fe-NPC and commercial Pt/C; (b) RDE voltammograms on the N,P,Fe-NPC electrode at various rotation speeds; (c) Koutecky-Levich plots at different potentials; (d and e) RDE voltammograms for typical N,P,Fe-NPC and Pt/C with and without methanol (1 M); (f) RDE voltammograms for the N,P,Fe-NPC electrode after 0 and 6000 cycles.

molecules. $^{26,32}$ From Fig. 5d and e, we inferred that typical N,P,Fe-NPC had excellent tolerance to methanol. Moreover, stability is another important requirement for ORR electrocatalysts in the practical application of fuel cells. ${ }^{31,39}$ The electrochemical stability of typical N,P,Fe-NPC was studied by continuous potential cycles between 0.55 and $0.95 \mathrm{~V}$ (vs. RHE) with a scanning speed of $50 \mathrm{mV} \mathrm{s}{ }^{-1} \cdot{ }^{40}$ From Fig. 5f, only $14 \mathrm{mV}$ negative shift of the half-wave potential occurred after 6000 cycles, which revealed that typical N,P,Fe-NPC had excellent durability. Therefore, we can conclude that typical N,P,Fe-NPC has the characteristics of outstanding catalytic ability, stability and endurance to methanol.

There could be three probable reasons for the dual activities for ORR and HER. First, the typical N,P,Fe-NPC electrode has high surface area (BET surface area of $776.68 \mathrm{~m}^{2} \mathrm{~g}^{-1}$ and electrochemical surface area of $55.0 \mathrm{mF} \mathrm{cm}^{-2}$ ) and many pores and nanopores; these can easily expose the active sites (for both ORR and HER) for the reaction and facilitation of high mass transfer fluxes, resulting in accelerated reactant and electron transport. ${ }^{17,18,41}$ Second, the co-doping of $\mathrm{N}$ and $\mathrm{P}$ elements greatly contributes to the electrochemical activity; ${ }^{25}$ especially, the pyridinic nitrogen contributes to the electrochemical activity, and graphitic nitrogen is very important for the improvement in the reduction current. ${ }^{4}$ Finally, the co-doping of $\mathrm{N}$ and Fe can synergistically enhance ORR activities. The doped $\mathrm{N}$ and Fe can form active sites $\left(\mathrm{FeN}_{x}\right)$, which are very helpful for the ORR activity. ${ }^{25,42}$

\section{Conclusions}

In this paper, we designed the bulk preparation of low-cost, simple, and non-precious metal catalysts using widely available and recyclable Pueraria lobata powder as the carbon source. The typical product was $\mathrm{N}, \mathrm{P}$ and $\mathrm{Fe}$ co-doped nanoporous carbon (N,P,Fe-NPC) with high surface area (BET surface area of $776.68 \mathrm{~m}^{2} \mathrm{~g}^{-1}$ and electrochemical surface area of $55.0 \mathrm{mF} \mathrm{cm}^{-2}$ ) and many nanopores. The typical N,P,Fe-NPC sample simultaneously exhibited high activities for oxygen reduction and hydrogen evolution reactions. Due to the high surface area and the tri-doping of N, P and Fe elements, N,P,FeNPC may have applications in other fields such as gas uptake, sensors, sewage treatment, and supercapacitors.

\section{Conflicts of interest}

There are no conflicts to declare.

\section{Acknowledgements}

We acknowledge the funding support from National Natural Science Foundation of China (Grants 21771002, 21271005), Project of Anhui University (02303203-0054), Talent Project of Education Department of Anhui Province (gxyqZD2016010) and Natural Science Foundation of Education Department of Anhui Province (KJ2017A574).

\section{References}

1 G. Wu, K. L.More, C. M.Johnston and P. Zelenay, Science, 2011, 332, 443.

2 M. K. Debe, Nature, 2012, 486, 43.

3 K. P. Gong, F. Du, Z. H. Xia, M. Durstock and L. M. Dai, Science, 2009, 323, 760. 
4 D. H. Guo, R. Shibuya, C. A. kiba, S. Saji, T. Kondo and J. Nakamura, Science, 2016, 351, 361.

5 J. N. Guo, M. Y. Ning and Z. H. Xiang, J. Energy Chem., 2017, 26, 1168.

6 C. Tang, B. Wang, H. F. Wang and Q. Zhang, Adv. Mater., 2017, 29, 1703185.

7 H. H. Wu, X. L. Jiang, Y. F. Ye, C. C. Yan, S. H. Xie, S. Miao, G. X. Wang and X. H. Bao, J. Energy Chem., 2017, 26, 1181.

8 H. W. Liang, S. Bruller, R. H. Dong, J. Zhang, X. L. Feng and K. Mullen, Nat. Commun., 2015, 6, 7992.

9 M. S. Faber and S. Jin, Energy Environ. Sci., 2014, 7, 3519.

10 Z. W. Seh, J. Kibsgaard, C. F. Dickens, I. B. Chorkendorff, J. K. Norskov and T. F. Jaramillo, Science, 2017, 355, 146.

11 J. H. Wang, W. Cui, Q. Liu, Z. C. Xing, A. M. Asiri and X. P. Sun, Adv. Mater., 2016, 28, 215.

12 J. Greeley, I. E. L. Stephens, A. S. Bondarenko, T. P. Johansson, H. A. Hansen, T. F. Jaramillo, et al., Nat. Chem., 2009, 1, 552.

13 Z. L. Wang, X. F. Hao, Z. Jiang, X. P. Sun, D. Xu, J. Wang, et al., J. Am. Chem. Soc., 2015, 137, 15070.

14 M. Zhou, H. L. Wang and S. J. Guo, Chem. Soc. Rev., 2016, 45, 1273.

15 Y. Zheng, Y. Jiao, M. Jaroniec, Y. G. Jin and S. Z. Qiao, Small, 2012, 8, 3550.

16 Y. G. Li, W. Zhou, H. L. Wang, L. M. Xie, Y. Y. Liang, F. Wei, et al., Nat. Nanotechnol., 2012, 7, 394.

17 P. Chen, T. Y. Xiao, Y. H. Qian, S. S. Li and S. H. Yu, Adv. Mater., 2013, 25, 3192.

18 P. Chen, L. K. Wang, G. Wang, M. R. Gao, J. Ge, W. J. Yuan, et al., Energy Environ. Sci., 2014, 7, 4095.

19 K. H. Wong, G. Q. Li, K. M. Li, V. Razmovski-Naumovski and K. Chan, Food Chem., 2017, 231, 231.

20 M. H. Rashid, M. N. Uddin, T. Asaeda and R. W. Robinson, Weed Biol. Manage., 2017, 17, 103.

21 R. D. Tanner, S. S. Hussain, L. A. Hamilton and F. T. Wolf, Econ. Bot., 1979, 33, 400.

22 Z. Y. Wu, P. Chen, Q. S. Wu, L. F. Yang, Z. Pan and Q. Wang, Nano Energy, 2014, 8, 118.
23 G. Wang, W. H. Wang, L. K. Wang, W. T. Yao, P. F. Yao, W. K. Zhu, et al., J. Mater. Chem. A, 2015, 3, 17866.

24 X. J. Huang, Y. G. Tang, L. F. Yang, P. Chen, Q. S. Wu and Z. Pan, J. Mater. Chem. A, 2015, 3, 2978.

25 W. Wan, Q. Wang, L. Zhang, H. W. Liang, P. Chen and S. H. Yu, J. Mater. Chem. A, 2016, 4, 8602.

26 L. Zhang, H. Wang, H. Wang, X. P. Liu, L. Su, L. Yu, et al., J. Electrochem. Soc., 2016, 163, H738.

27 W. H. Niu, L. G. Li and X. J. Liu, J. Am. Chem. Soc., 2015, 137, 5555.

28 F. Jaouen, M. Lefevre, J. P. Dodelet and M. Cai, J. Phys. Chem. $B, 2006,110,5553$.

29 F. Jaouen, F. Charreteur and J. P. Dodelet, J. Electrochem. Soc., 2006, 153, A689.

30 D. S. Geng, Y. Chen, Y. G. Chen, Y. L. Li, R. Y. Li, X. L. Sun, et al., Energy Environ. Sci., 2011, 4, 760.

31 C. Z. Zhu, H. Li, S. F. Fu, D. Du and Y. H. Lin, Chem. Soc. Rev., 2016, 45, 517.

32 J. Liang, Y. Jiao, M. Jaroniec and S. Z. Qiao, Angew. Chem., Int. Ed., 2012, 51, 11496.

33 H. X. Zhong, J. Wang, Y. W. Zhang, W. L. Xu, W. Xing, D. Xu, et al., Angew. Chem., Int. Ed., 2014, 53, 14235.

34 Y. Y. Liang, Y. G. Li, H. L. Wang, J. G. Zhou, J. Wang, T. Regier, et al., Nat. Mater., 2011, 10, 780.

35 Q. Wang, Z. Y. Zhou, Y. J. Lai, Y. You, J. G. Liu, X. L. Wu, et al., J. Am. Chem. Soc., 2014, 136, 10882.

36 R. E. Davis, G. L. Horvath and C. W. Tobias, Electrochim. Acta, 1967, 12, 287.

37 M. K. Tham, R. D. Walker and K. E. Gubbins, J. Phys. Chem., 1970, 74, 1747.

38 W. Yang, T. P. Fellinger and M. Antonietti, J. Am. Chem. Soc., 2011, 133, 206.

39 W. X. Yang, X. J. Liu, X. Y. Yue, J. B. Jia and S. J. Guo, J. Am. Chem. Soc., 2015, 137, 1436.

40 H. W. Liang, X. D. Zhuang, S. Bruller, X. L. Feng and K. Mullen, Nat. Commun., 2014, 5, 4973.

41 G. J. Tao, L. X. Zhang, L. S. Chen, X. Z. Cui, Z. L. Hua, M. Wang, et al., Carbon, 2015, 86, 108.

42 Y. Zheng, Y. Jiao and S. Z. Qiao, Adv. Mater., 2015, 27, 5372. 